\title{
More than Moore's Mores: Computers, Genomics, and the Embrace of Innovation
}

\author{
JOSEPH NOVEMBER (1) \\ Department of History \\ University of South Carolina \\ Columbia, $S C$ \\ USA \\ E-mail: november@sc.edu
}

\begin{abstract}
The genomics community has frequently compared advances in sequencing to advances in microelectronics. Lately there have been many claims, including by the National Human Genome Research Institute (NHGRI), that genomics is outpacing developments in computing as measured by Moore's law - the notion that computers double in processing capability per dollar spent every 18-24 months. Celebrations of the "\$1000 genome" and other speed-related sequencing milestones might be dismissed as a distraction from genomics' slowness in delivering clinical breakthroughs, but the fact that such celebrations have been persistently encouraged by the NHGRI reveals a great deal about the priorities and expectations of the American general public, the intended audience of the genomics-computing comparison. By delving into the history of speculative thinking about sequencing and computing, this article demonstrates just how much more receptive to high-risk/high-payoff ventures the NIH and the general public have become. The article also provides access to some of the roots and consequences of the association of "innovation talk" with genomics, and the means to look past that association to the less glamorous (but arguably much more important) contributions of the NHGRI to building the field of genomics.
\end{abstract}

Keywords: Genomics, Genome, Sequencing, Microelectronics, Microprocessors, NHGRI, National Human Genome Research Institute, NIH, National Institutes of Health, Moore's law, Gordon Moore, Computers, Robert Ledley, \$1000 genome, Innovation, Human Genome Project, High-speed, Speed, Maintenance, Carlson Curve

What follows is a story of how a risky, expensive, and long-term effort persisted in an environment that has heavily favored safe, cheap endeavors that quickly produce appreciable results. There is a version of this story that reads a lot like "The Emperor's New Clothes," where the emperor has been replaced by the American public and the bespoke,

The original version of this article was revised due to a retrospective Open Access order. 
visible-only-to-the-worthy clothes have become the just-over-the-horizon "personalized medicine" and other promised but undelivered fruits of genomics. That version, though politically useful to skeptics of genomics, is unfair and unhelpful. Rather, this story is a tale of survival, in which scientists devised a tool that has allowed them to convince the American public to do the thing it likes least: wait. Americans' patience, it turns out, could be bought by persuading them that they were on the cusp of something amazing. For many Americans the speed-up of computers over their lifetimes has been a transformative and generally positive experience. Genomics, they were promised, would be even better.

"We have put Moore's law to shame," proclaimed Dr. Alan E. Guttmacher, MD at the 2009 annual meeting of the National Coalition for Health Professional Education in Genetics (Guttmacher, 2009). ${ }^{1} \mathrm{He}$ was comparing the historical speed-up and economization of nucleic acid sequencing to Gordon Moore's famous 1965 observation that computing power per dollar spent effectively doubles every 2 years. And in that comparison sequencing had come out far ahead. Guttmacher was not alone in subjecting Moore's law to "playful abuse." According to Nature dozens of similar claims have recently been made by leading figures in genomics (Hayden, 2014, p. 294). Most prominent among them is the biggest funder of genomics, the National Human Genome Research Institute (NHGRI), which is part of the US federal government's National Institutes of Health (NIH) and which is best known for its leadership of the Human Genome Project.

Over the past few years, the NHGRI has made a persistent effort over to let the public know that advances in sequencing are outpacing advances in computer processors. On a regularly updated and highly accessible (both in terms of reachability and language) webpage hosted at genome.gov and titled "The Cost of Sequencing a Human Genome," the NHGRI showcases the strides made in sequencing. Among the first things a visitor sees is a colorful graph showing that between 2001 and 2015 the "cost per genome" has decreased several orders of magnitude more than the cost of computer processing power - as measured by Moore's law decreased during the same period (Figure 1) (NHGRI, 2016b). A human genome that was sequenced in 2001 for $\$ 100$ million was sequenced in 2007 for about $\$ 10$ million and in 2015 for just over $\$ 2000$.

Far from a playful claim circulated only among specialists, the genome.gov page carefully explains to readers how sequencing costs

${ }^{1}$ Guttmacher presented a similar version of this talk, which includes the line "we have put Moore's law to shame," to the National Academies of Science, Engineering, and Medicine on 31 August 2009. 


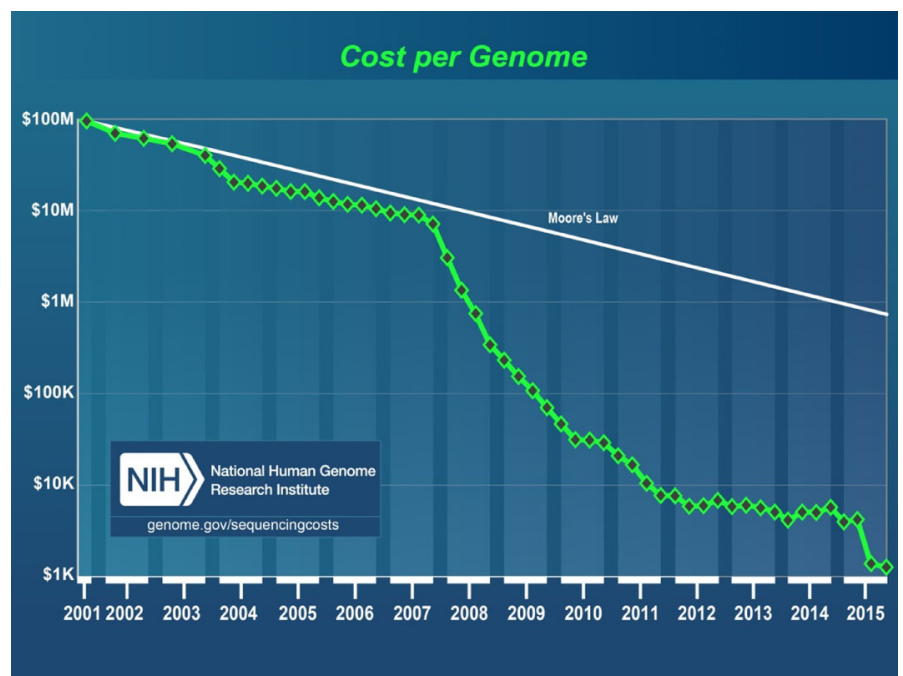

Figure 1. NHGRI comparison of "cost per genome" and Moore's law (genome.gov/ sequencingcosts). Note that starting around 2007, "cost per genome accelerates away from Moore's law

were estimated and provides "A primer about genome sequencing" to familiarize readers with the methods, terms, and goals of genomics. Anyone clicking on the actual chart is brought to a page titled "DNA Sequencing Costs: Data," which breaks down, in lay language, the way the institute assesses sequencing costs (direct and indirect), standards of quality, and "coverage" (the number of times a particular set of DNA bases is re-sequenced). Readers are encouraged to distribute the information published on the page, and are even given specific instructions on how to formally cite the material there (Wetterstrand, 2016).

Like the many charts conveying Moore's law, the Cost per Genome chart uses a logarithmic scale on its vertical axis. And like the Moore's law charts, this one comes with plenty of disclaimers. "Cost," it turns out, is an aggregate measure of a wide range of expenditures, but it nevertheless excludes many arguably related activities:

Accurately determining the cost for sequencing a given genome (e.g., a human genome) is not simple. There are many parameters to define and nuances to consider. In fact, it is difficult to cite precise genome-sequencing cost figures that mean the same thing to all people because, in reality, different researchers, research institutions, and companies typically track and account for such costs in different fashions. (NHGRI, 2016) 
By the NHGRI's own account, the charts comparing progress in sequencing to Moore's law are informal and arbitrary. The issue of Moore's law being a crucial component of the speed-up of sequencing is glossed, as is the question of agency - that is, who is actually responsible for the speed-up. Historian Hallam Stevens points out in "Dr. Sanger, meet Mr. Moore" that "taking seriously the analogy with semi-conductor electronics suggests that market forces may be seeding changes in who, how and where biology is done..." - such forces get scant mention in the NHGRI's accounts of the speed-up (Stevens, 2011, p. 105). ${ }^{2}$ Setting aside the problems of agency and self-reference, the institute does nevertheless keep its Moore's law vs. sequencing charts updated and it does present them as a resource for the press and the general public to understand "innovation in genome-sequencing technologies and strategies" (NHGRI, 2016a). In short, the NHGRI and the federal agency of which it is part, the NIH, appear to be trying to convince the tax-paying public to view genomics as they view computer technology: as an exceptionally innovative and historically transformative science.

\section{Moore's Law as the Strategic Defense of Genomic Science}

The cynical take on the NHGRI's - and the larger genomics community's - boasts about outpacing Moore's law is that they serve as distractions from the continuing sluggishness of genomics when it comes to delivering meaningful clinical advances. Even if sequencing a human genome costs a miraculously low $\$ 1000$, there remains the question of how to make genomic data useful to patients. As Nature's Erika Check Hayden bluntly put it: "Now that sequencing is cheap enough to talk about scanning every patient's genome, or at least the protein-coding portion of it, it is still not clear how that information will translate into improved care" (Hayden, 2014). Along the same lines, in 2014 The Journal of the American Medical Association contradicted many of the excited claims emanating from genomicists when it urged physicians to "proceed with care" in cases where they might consider using interpreted genomic sequence information. This warning came in the same issue of JAMA in which Stanford-based physicians published a small descriptive study that showed whole-genome sequencing leading to little more than confusion and waste when used in a clinical setting. Particularly vexing, JAMA noted, was the "absolutely staggering" number of

${ }^{2}$ Gordon Moore, it should be noted, holds a Ph.D. in chemistry (Caltech) and is just as much a "doctor" as Frederick Sanger. 
unique variations found in each patient's genome; tools for interpreting these variations remain to be developed. Putting genomics to work had, according to $J A M A$, neither reduced uncertainty in medical decision making nor improved clinical outcomes. All that said, JAMA also indicated that it held great hope for the clinical usefulness of genomics in the future (Feero, 2014, pp. 1017-1019). ${ }^{3}$

$J A M A$ 's criticism of genomics is not an isolated case, and the NHGRI's response to such doubts has been to ask the medical community and the general public for patience. Notably, in a widely-cited 2011 Nature research perspective article, "Charting a course for genomic medicine from base pairs to bedside," the NHGRI encouraged anyone hoping genomics to have a noticeable impact on "improving the effectiveness of healthcare" to look to "beyond 2020." An illustration (see Figure 2) in that article shows the NHGRI's timeline for when to expect genomics to become the basis of research that would be "advancing the science of medicine" and research that would be "improving the effectiveness of healthcare" (Green et al., 2011, p. 206).

The medical revolutions predicted by genomics (and particularly by the NHGRI) may indeed still be far away, but there is much more to the genomics-computing comparison than a mere distraction from disappointing clinical progress. Delving into the comparison's history, by drawing from documents provided by the National Human Genome Research Institute Archive and by the National Biomedical Research Foundation, shows that well before Moore's Law, sequencing pioneers saw a direct connection between computing processing power and their own goals as researchers. However, when these pioneers sought to justify investments in technological development on the basis of nearlyunfathomable work speed-ups those investments would supposedly bring about, they were met with an overwhelmingly hostile response. Thus, while the excited talk of the 1950s about using technology to greatly accelerate research may resonate with similar rhetoric today, the reception of this message is much more sympathetic today than it was a half-century ago.

Unpacking the NHGRI's forward-looking presentation of (and to a large degree decision-making about) genomics, especially the institute's prioritization of the concept of "innovation," reveals a great deal about the agendas and expectations of the intended audience of the genomicscomputing rhetoric. That audience, which includes not only scientists

3 Another prominent example of a skeptical but hopeful view of the clinical application of genomics is: Maughan (2017). 

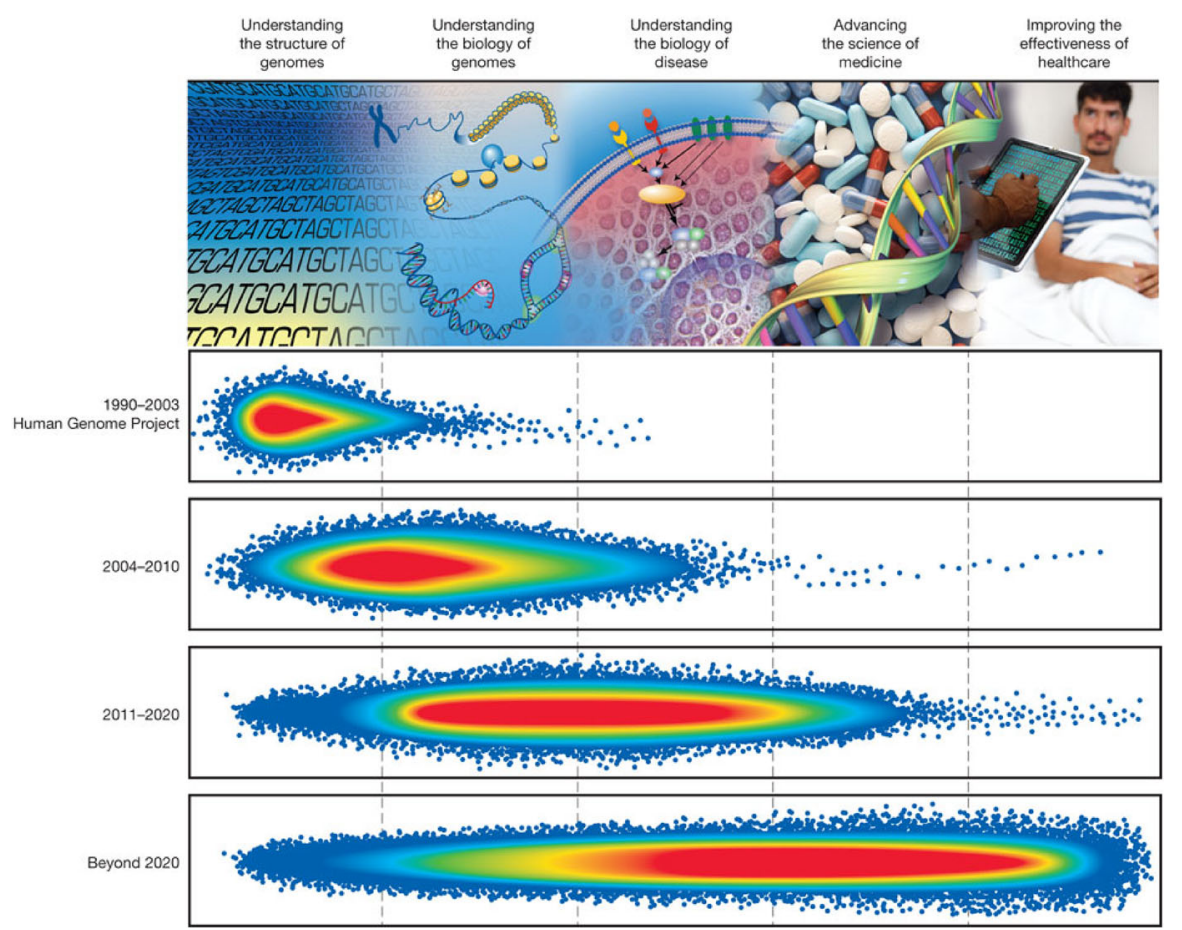

Figure 2. Green et al. (2011): "Schematic representation of accomplishments across five domains of genomics research." Even in the "open-ended" "Beyond 2020 category, the "improving the effectiveness of healthcare" category seems under-represented

and physicians but also the administrators, legislators, philanthropists, and (most importantly) the American general public who fund genomics research, has exhibited a great deal of faith in the importance of and goodness inherent in innovation. They have also, in many aspects of their lives, experienced firsthand the rapid changes brought about by the speed-up and economization of computers. When Moore's law is evoked, they tolerate the many setbacks associated with developing new technologies because they expect a life-changing (or at least significantly labor-saving) payout in the foreseeable future.

\section{Moore's Exceptionalism in the Era of Innovation}

Successfully selling genomics by comparing it favorably to Moore's law is predicated on one's audience being already subscribed to a very particular set of priorities and expectations when it comes to making 
decisions about committing to using and investing in an emerging technology. Briefly examining the history of Moore's law, especially its exemplary status in the sorts of discussions that have fueled so many Americans' (and others') fervor for innovation, goes a long way towards showing what NHGRI has accomplished by framing progress in genomics in terms of Moore's law.

Moore's law is not a law of nature, but rather one of economics or human behavior. Specifically, it stems from a 1965 think-piece written by Intel co-founder Gordon E. Moore, titled, "Cramming More Components onto Integrated Circuits," for the trade journal Electron$i c s$, in which he set forth the notion that the number of transistors built into an integrated circuit doubles roughly every year - in 1975 he revised his estimate downward to every 2 years (Moore, 1965, p. 114). Since the late 1970s, Moore's "law" became widely accepted as the benchmark for how computers would change, and how they would, in turn, change the world.

Though the "change the world" component of Moore's law may seem to be a stretch, it was part of his thinking from the beginning. And it was - and still very much is - the part the American general public finds exciting. Moore's paper boldly concluded: "In summary, integrated circuits will allow the advantages of electronics to be applied generally throughout society." And he left readers to consider the following: "The future of integrated circuits is the future of electronics itself. The advantages of integration will bring about a proliferation of electronics, pushing this science into many new areas. Integrated circuits will lead to such wonders as home computers - or at least terminals connected to a central computer - automatic controls for automobiles, and personal portable communications equipment" (Moore, 1965, p. 117). This was a big claim in the era of batch-processing mainframes that cost millions and filled large rooms.

Over the past decades, computers have indeed shrunk in cost and size while speeding up dramatically. This same process is now being used as a benchmark to measure the progress of another activity that promises to change the world: sequencing. Even if one takes into consideration the role of computing advances in the speed-up of sequencing, the comparison is of two almost wholly different phenomena. Yet the comparison remains compelling. Unpacking Moore's law and its reception goes a long way towards explaining why genomicists would crow about beating Moore's law and why the public is so willing to entertain such claims. 
By itself, Moore's law has no meaning. The speed-up of processors per dollar spent on them only matters to consumers when they experience the consequences of that speed-up. Sometimes the consequences are negative, such as one's desktop computer becoming obsolete just a few years after it was purchased. But other times, the consequences are positive: calculations that took years to run a decade ago now take only hours; and the real-time graphical user interface evolved in a matter of decades from a wild fantasy to something that is so easily obtained that it is almost taken for granted.

What Moore's law is not is a scientific law. Rather, as historian of computing David Brock puts it, "Moore's law is a description of human activity as well as a statement about the inherent possibilities of silicon semiconductor manufacturing technology.... Moore's law is grounded in the ongoing efforts of technologists to push silicon integrated circuit manufacturing forward." Thus, realizing Moore's law has, since its inception, required a great deal of human agency. As Brock puts it, "Moore's law has not and will not happen on its own accord. It relies on large-scale efforts by technologists directed toward manufacturing the future it describes" (Brock, 2006, pp. 97, 99).

For Gordon Moore himself, the phenomenon he described was essentially economic. During a 2005 celebration of the 40th anniversary of Moore's law, he reflected, "Moore's law is really about economics... my prediction was about the future direction of the semiconductor industry, and I have found that the industry is best understood through some of its underlying economics" (Moore, 2006, p. 67). What had made Moore so bold in 1965 was that as an expert in microelectronics he saw that he and his colleagues had all of the conceptual tools to push computing into an era where a billion transistors could be cheaply packed into a tiny computer. "No barrier," he wrote, "exists comparable to the thermodynamic equilibrium considerations that often limit yields in chemical reactions; it is not even necessary to do any fundamental research or to replace present processes. Only the engineering effort is needed." From the perspective of 1965, that effort seemed daunting, and he said as much: "There remain many significant problems for the electronics industry to solve in attempting to take advantage of this evolving technology to supply the rapidly increasing electronic requirements of the world" (Moore, 1965, p. 117).

Overcoming what Moore glibly described as "significant problems" was, as historians of computing have shown, anything but inevitable. It took a great deal of organization and coordination, the success of which Brock attributes to the Semiconductor Industry Association's persis- 
tence in fostering the development of technologies and cultures that would allow Moore's law to become a reality: "The 'technology roadmap' created by the SIA not only explicitly transformed Moore's Law from a prediction to a self-fulfilling prophecy, it spelled out what needed to be accomplished, and when" (Brock, 2006, p. 93). For engineers and scientists working directly with semiconductors and for their managers, keeping Moore's law on track meant mastering new technologies to build each new generation of chips. Brock estimated that "thirteen doublings - assuming one doubling every 2 or 3 years on the trajectory of Moore's law - would constitute the length of a single technologist's career" (Brock, 2006, p. 104). The doublings did not take place in isolation. For instance, improvements in magnetic storage density (as described by "Kryder's law"), had to keep pace with Moore's law to make it relevant to consumers.

Hype, often intertwined with exaltations of innovation, has accompanied Moore's law for a long time as well, especially since the mid1970s when the start-up culture emerged. Steve Jobs's quasi-spiritual sales pitches often promised far more than was ever delivered, but despite Apple's turbulent history the "the world's most innovative company" found receptive audiences time and again (Safian, 2018). Likewise, Microsoft's recent advertisement campaign to promote its vague long-term plans to somehow bring artificial intelligence tools to market begins with the line, "Innovation, it's not just a word, it's an action" (Microsoft, 2018).

Biotech also has connections to the startup culture and its rhetoric. As Sally Smith Hughes shows in Genentech: The Beginnings of Biotech, the biomedical community was not only open to overexcited talk about the transformative potential of technology, but was also via fostering the exemplary 1976 startup Genentech, arguably the original driver of such talk's modern form (Hughes, 2011). A case can even be made that the biomedical variety of the tech hype goes much further than the grand promises coming out of the world of computing. Notably, Kaushik Sunder Rajan in Biocapital: The Constitution of Postgenomic Life provides evidence that in the run-up to the year 2000, excitement over the prospect of technological change combined with religious millenarian zeal made for a heady mix of expectation of a radicallychanged world, one in large part shaped by human control of genomic information (Sunder Rajan, 2006).

For the American public to even consider innovation as a worthy thing to fund, there would need to be in place widespread expectation that innovation is worthwhile to the point of being a priority over other 
activities that might be funded. Across most of the American political spectrum innovation is indeed embraced. In 2015, Barack Obama, an "innovation junkie" (McFarland, 2016), declared, "For an advanced economy such as the United States, innovation is a wellspring of economic growth and a powerful tool for addressing our most pressing challenges as a nation... In fact, from 1948 to 2012 over half of the total increase in U.S. productivity growth, a key driver of economic growth, came from innovation and technological change" (Office of the Press Secretary, 2015). Hillary Clinton vowed to continue the emphasis on innovation into her presidency, calling for "an ambitious national commitment to technology, innovation and entrepreneurship" (Hillaryclinton.com, 2016). And Donald Trump pushed for innovation as well, telling a meeting of Silicon Valley CEOs, "We want you to keep going with the incredible innovation. There's nobody like you in the world" (BBC, 2016).

For historians of technology Andrew Russell and Lee Vinsel, the pervasiveness of innovation talk is so pronounced that Americans (and many others) seem to have come to see innovation as good per se. "Entire societies," they argue, "have come to talk about innovation as if it were an inherently desirable value, like love, fraternity, courage, beauty, dignity, or responsibility. Innovation-speak worships at the altar of change, but it rarely asks who benefits, to what end?" (Russell and Vinsel, 2016). Further, as Russell and Vinsel point out, "innovation" is rarely defined in a precise way: "When Americans talk about technology, they often use 'innovation' as a shorthand. But 'innovation' refers only to the very early phases of technological development and use. It also tends to narrow the scope of technology to digital gadgets of recent vintage" (Russell and Vinsel, 2017). In an environment where "innovation" is valued, projects that credibly promise innovation attract funding, not just because of the perceived potential for change they embody, but also because they are perceived to have the potential to be exempt from economic, institutional, and social rules normally governing the consequences of human activity (Russell and Vinsel, 2018).

If ever there were a benchmark for innovation, Moore's law is it. Moore's law has long been compared to many other areas besides sequencing, often for the dual purpose of showing: (a) the exceptionalism of the development of microprocessors; and (b) the sluggishness and lack of imagination in other areas. Indeed, while the speed-up of sequencing may have "put Moore's law to shame," it is usually Moore's law that is trotted out to do the shaming. In 1997, Microsoft's Bill Gates 
famously applied Moore's law to other fields in order to cast the PC industry as exceptionally innovative:

The PC industry is different than any other industry. The volume, the openness, the innovation, it's really unequaled. In fact, comparisons are often done between this industry and others, and it's just stunning when you look at it. The price of a mid-sized auto, it's about double what it used to be. Cereal... has doubled in price. And if you take that and say, what would those prices be if it were like the PC industry, the car would cost about $\$ 27$, and the cereal would cost about one cent. So, I think there's a lot to be learned by watching how this industry has done what it's done. (Gates, 1997)

Other commentators connected to the computing industry have been far less subdued than Gates in their use of Moore's law as a means of putting other areas of technological development into hilarious and humiliating perspective. ${ }^{4}$

Living with rapid technological change has become a fact of life in societies where computers are important - obsolescence, which periodically wipes out expensive investments of resources and time, is tolerated because of the apparently transcendent benefits of making the effort to adopt whatever novel technology comes next. However, as the ludicrous comparisons of computing to other fields show, the rate of change described by Moore's law does not apply to most other areas, even when it takes into account embedded technology - e.g., a typical car with dozens of computers in it built in 2016 still performs about the same as a car built 50 years ago.

In biomedicine, the public's practical expectations regarding actual changes to their everyday lives are more in line with the changes expected of automobiles than to the changes expected of computing (Reiser, 2009). ${ }^{5}$ Compared to 50 years ago, lifespans are a few years longer (rather than a few orders of magnitude longer); and most of the diseases that felled people 50 years ago remain lethal (albeit somewhat more manageable). But, that there remains hope that the kind of changes brought about by computing can indeed produce transcen-

4 Bill Gates's comment spawned several urban legends involving champions of one industry or other defending their products from consumers expecting to see advances similar to that in computing. See: Snopes.com, "General Motors Replies to Bill Gates," URL: http://www.snopes.com/humor/jokes/autos.asp.

${ }^{5}$ Reiser (2009) shows that even when new technologies (other than electronic computers) are introduced to medicine, public expectations and practitioner rhetoric are quite subdued compared to the discourses surrounding the use of computers, genomics, and nanotechnology in medicine. 
dental breakthroughs in medicine. There is, for example, widespread hope - now backed by legislation - that great changes could be brought to healthcare by forcing the transformative technology of computers onto it (November, 2016, p. 3). The place where the greatest public expectations lie, though, is an emerging medical research field that arguably could not exist without computers: genomics. Along with putting computers to use, genomicists have put the rhetoric of computing to use, a move that has deeply shaped how genomics is promoted and perceived.

\section{The Need for Speed}

Getting the American public and its representatives on Capitol Hill to commit to developing genomics to the point where it is accessible and clinically useful has been extremely challenging for the NHGRI. Longterm planning is not compatible with the norm in Washington of looking to the immediate future, or at least not beyond one's current Congressional term. One way of keeping the public and fund-controlling legislators engaged, as this article explores, was to recast genomics in such a way where short-term progress is not only evident but indeed worthy of celebration. Rather than focus on medical breakthroughs or even advances in knowledge, the NHGRI - and the Human Genome Project before it - focused on speed, that is, how rapidly and cheaply one could determine the sequence of bases in whatever strand of DNA being examined.

As historian Michael Fortun pointed out in 1999, genomics has since its beginnings used speed and economization as its measure of progress. Partly this was due to a lack of coherence in the mission of the Human Genome Project, which he holds was not about "humans," was not confined to "genomics," and was not a recognizable "project":

Despite incessant references by journalists, scientists, and many of us in the science studies community to this unity vehicle signified by those three capital letters HGP, and despite the persistence of such control metaphors as James Watson or Francis Collins being 'at the helm' or 'taking the reins' the vehicle and its driver are only there in the way that subatomic particles are 'there:' as a ceaseless flow arrested by the mechanical assemblages of the observers for particular rhetorical, that is to say, pragmatic ends. Study of the 'Human' has actually dispersed into a zoo blot of research organisms - yeast, mice, C. elegans, Drosophila - each of which attracts 
its own degree of attention and funding, and which hybridize with the 'Human' either in the (real) space of the laboratory or in the (virtual) space of the genetic databases. The 'Genome,' too, loses its distinctly defined boundaries, dispersed into technology itself; what is desired is not so much genomes as it is genomics, the assemblage of techniques, tools, and concepts for producing, analyzing, and manipulating genomics. And the postulated coherence of a localizable, definable 'Project,' with a manageable completed endpoint the 'Holy Grail' of a totally mapped, totally sequenced genome - is a fantasy whose primary function is providing coherence and closure to an epic narrative - a narrative that holds a good deal of exchange value with congressional patrons. (Fortun, 1999, p. 26) ${ }^{6}$

In the absence of a clear goal - other than the very distant promise of major medical advances - sequencing speed had become a goal unto itself. As Fortun put it, the name "Human Genome Project" could be "revised to a read 'a project to map and sequence the entire human genome as fast as we possibly can.' 'Projecting Speed Genomics' would be a more appropriate moniker" (Fortun, 1999, p. 27). As early as 1986, Fortun shows, genomics pioneer Walter Gilbert had called for the Human Genome Project to orient itself towards speeding up sequencing to the point where a "draft" of the human genome could be mapped within a "scientist's immediate lifetime," (i.e., the year 2000) (Fortun, 1999 , p. 36). That goal was reached amid great fanfare, and fortunately for the prospect of convincing the public of the continued worth of "speeding up" as a goal in its own right, even after the draft sequence had been completed in 2000 , that public was already familiar with one historical measure of increasing speed: Moore's law. And it is therefore unsurprising that since 2000 analogizing the advances in sequencing to the advances in microelectronics has helped to promote the notion that the investment will pay off transformationally in the long run.

For the typical patient, the payoff of investing in genomics has yet to arrive, at least not in a way that is comparable to the changes computing generally brought to their lives. By around 1980, 15 years after Moore's law was published, the speed-up of microprocessors could be connected to the spread of computers to millions of offices and homes. Though the acceleration of sequencing has been even more rapid than that of microelectronics, in the fifteen or so years since sequencing has supposedly outpaced computing, there has been little sign of the equivalent

${ }^{6}$ Fortun called this assessment an "overstatement," but from the perspective of 2018 his tongue-in-cheek take on the direction of the Human Genome Project seems to have been imitated by reality. 
of a personal computer or a "killer app" (like the 1979 VisiCalc spreadsheet program, which sold about a million copies and which prompted hundreds of thousands to buy their first home computer) to motivate consumers to bring genomics into their lives (Zynda, 2013, p. 68 ). As of 2018, the most widely recognized genomics products are testing services from Ancestry.com and 23andMe. At this point Ancestry's tests only serve to identify the consumer's genetic relatives and their racial and/or ethnic ancestry. 23andMe provides similar services, with the option of testing for ten diseases and conditions 23andMe limited its test to assessing risks rather than establishing diagnoses after the company was warned by the Food and Drug Administration (FDA) that marketing its tests as clinically useful was illegal (Gutierrez, 2013).

Despite the warnings and disclaimers, public excitement about genomics remains and is indeed being stoked by genomicists and America's political leadership. Personalized medicine, which uses genomic and other data to optimize a patient's diagnosis and treatment, has been hotly anticipated but stubbornly unrealized since the late 1990s. The same leading genomicists pushing the Moore's law comparison have over the last 20 years been raising patients' hopes for a new, personal kind of medicine. In 2010, Alan Guttmacher, along with Amy McGuire, Bruce Ponder, and Kári Stefánsson, published an article in Nature Reviews Genetics titled, "Personalized genomic information: preparing for the future of genetic medicine," which began with the assumption that "we are rapidly approaching an era in which access to personalized genomic information is likely to be widespread" (Guttmacher et al., 2010).

Five years and not much practiced personalized medicine later, the NIH rebranded personalized medicine as "precision medicine" and launched the Precision Medicine Initiative (PMI), which was formally introduced by President Barack Obama in his 20 January 2015 State of the Union Address. In their description of the PMI, NIH Director Francis Collins and former NIH Director (and Nobel Laureate) Harold Varmus called for the FDA to "make sure its oversight of genomic technology supports innovation," and predicted that "Although the precision medicine initiative will probably yield its greatest benefits years down the road, there should be some notable near-term successes" (Collins and Varmus, 2015). In 2017, while waiting for these "near-term successes" to materialize, the federal government's Office of the National Coordinator for Health Information Technology announced that "The Precision Medicine Era is Dawning," and declared that "The PMI 
will usher in an era of individualized health care. PMI will advance the nation's ability to accelerate scientific discovery and improve clinical care through an innovative approach that takes into account individual differences in people's genes, environments, and lifestyles" (Caban and Chaney, 2017). Such overexcited talk about an imminent transformation of medicine by computers and sequencing is not new, however, and a look at how it was received back in 1950s and 1960s reveals that much has changed in terms of public expectations and priorities.

\section{Looking Ahead from Before the Start}

Speculative, grandly historical talk about sequencing and electronic computing goes back to the mid-1950s, when both fields were emerging and when Moore's 1965 white paper was still a decade away. Thus, the recent appropriation of Moore's law as a benchmark to measure the progress of sequencing technology is less a case of borrowing from computing than it is a hearkening back to the early days of both fields. Even before 1961, when Marshall Nirenberg and Heinrich Matthei cracked the genetic code (i.e., finding which configuration of nucleotide bases determines which amino acids), there was a substantial volume of published work on the subject of sequencing, both of amino acids (in proteins) and nucleotide bases (in nucleic acids DNA and RNA). Ultimately, protein sequencing and nucleic acid sequencing would become activities quite distinct from each other, but in the earliest days amid the confusion about how DNA coded for proteins, there was a great deal of overlap in what historian Miguel Garcia-Sancho helpfully labels "molecular sequencing" (Garcia-Sancho, 2012).

For Robert Ledley (1926-2012), solving the genetic code and sequencing each appeared to be tasks to which one could fruitfully apply digital electronic computers. Like many others in the earliest days of sequencing, Ledley's background was unconventional. A licensed dentist with graduate-level training in physics and experience programming some of the earliest computers, Ledley found his way to sequencing via his early 1950s work with computers at the Johns Hopkins University Office of Operations Research. One of his colleagues there, Big Bang cosmologist (and scientific gadfly) George Gamow, was in the process of attaching himself to and organizing many of the pioneers of what would become molecular biology. In 1954, Ledley joined Gamow's RNA Tie Club, a group of select individuals, including James Watson, Francis Crick, Sydney Brenner, Max Delbrück, and 
Richard Feynman, dedicated to figuring out how DNA relates to RNA and proteins. Ledley's major contribution to the Tie Club's effort were several contingency tables (which would serve as the basis of a computer program) matching three-letter sequences of nucleotide bases (triplets) to amino acids. Ledley's program not only took into account the possibility that DNA is "read" in a simple, sequential manner of one nonoverlapping triplet of bases after another (which is what Nirenberg and Matthai eventually found to be the case) but also the possibilities that triplets could overlap or be built from non-sequential bases (Ledley, 1955, p. 506).

From a programming standpoint, Ledley explained when he published his work in 1955 in the Proceedings of the National Academy of Sciences, his scheme was straightforward. A general-purpose electronic digital computer could run the program without needing any special equipment or alterations. The drawback was that even on the fastest computers then reasonably imaginable, the program took a very long time to run. As Ledley saw it, there were 20 ! $(\sim 2.432902 \mathrm{e}+18)$ combinations the program needed to test, and "to try 20 ! solutions, a computer put to work in the days of the Roman Empire, at the rate of one million solutions per second, $24 \mathrm{~h}$ a day, all year round, would not yet be close to finishing the job" (Ledley, 1955, p. 511).

Thousands of years may seem like a long time but in 1955 "one million solutions per second" was a fantastical figure - running the program on the machines available at the time would have taken several orders of magnitude longer. If, for the sake of arriving at a very rough estimate, one were to equate "one million solutions per second" to "one million instructions per second" (MIPS), then the UNIVAC I (0.002 MIPS) would get the job done in a few million years. Only in the early 1970s did high-end (mutli-million-dollar) commercially-sold computers come close to the 1 MIPS mark - the IBM System 370/158 clocked in at 0.64 MIPS (Wikipedia, "Instructions Per Second"). ${ }^{7}$

Ledley's program may have been unfeasible to run, but he continued to actively seek out support for plans to apply computer technology to problems related to various forms of sequencing even after he drifted

${ }^{7}$ By the early 1980s, computers capable of running more than 1 MIPS were commonplace; Intel's 286 microprocessor (1982) ran at 1.28 MIPS. A decade later, Intel's 486 chips could run from between 11.1 and 25.6 MIPS. Today's speeds are staggering by comparison - to the point of making Ledley's fantasies fantastically quaint. The Intel Core i7 6950X, a chip found in fancier home desktop computers circa 2016, runs at 317,900 MIPS. A program that took a geological age to run on a UNIVAC, and millennia to run on an IBM 370, would take mere months to run on today's home computer. 
away from the RNA Tie Club. In the late 1950s, Ledley was working as a professor at George Washington University School of Engineering and Applied Science while also trying to establish a non-profit organization called the National Biomedical Research Foundation (NBRF), the mission of which was to "stimulate biomedical research scientists to utilize computers by setting an example through its own pioneering research and development in new areas of computer applications" (Ledley et al., 1973). To secure funding for the NBRF, Ledley sought support - in the form of a large research grant - from the NIH - to build a "Biomedical Computer and Biomathematics Research Center." One of major activities of that center would be using computers to do sequencing.

Ledley's grant application, which was submitted in 1959, predated early planning for the establishment of the NHGRI by almost 30 years. Ledley's application was quickly and categorically rejected by the NIH, the same agency that would later go on to embrace and even foster bioinformatics. Partly, one can reasonably attribute the NIH's rejection of Ledley's grant to its lack of feasibility, especially given how uncertain the future of computing looked from 1959 (Haigh, 2001). ${ }^{8}$ But in the decades since 1959, the agency - and one could argue the broader society - have become much more tolerant of and indeed kindly disposed towards speculation about the future of both computing and sequencing.

In contrast to the NIH of the late 1980s, when enthusiasm for the use of computers in biomedical research - as well as for the forward-looking rhetoric associated with computing culture - was mounting, the NIH of the late 1950s was largely hostile to computing and to speculative talk about the potential of computers, especially when combined with medicine. At the time, the few computing projects on the NIH campus were sponsored by the Office of Director, and without homes in any particular institutes they were very much ephemeral ventures.

In the late 1950s, NIH Director James Shannon (1904-1994) was very much the odd man out at the agency when it came to using digital computers for biomedical research. He held an "expectation that this powerful and new technology [electronic computers] would not only facilitate the solution of problems as currently formulated, but also, like the telescope, would permit the exploration of phenomena otherwise unapproachable" (Shannon, 1965, p. xi). Such enthusiasm had initially

${ }^{8}$ Haigh (2001) shows that early proposals to adopt electronic computers were commonly fraught with doubts about the "feasibility" of using such machines productively. 
grown not out of any scientific work Shannon had seen done with computers, but rather by the benefits he saw computers bring to administrative work. Shortly after becoming NIH Director in 1955, Shannon attended a one-week intensive workshop run by IBM Laboratories on the potential of computers in science, and returned from it hoping to bring computers to researchers.

The various NIH research institutes were not receptive to Shannon's plans to bring a computer to the agency's campus. His 1956 effort to acquire an IBM 650, the company's first mass-produced electronic computer and one of its relatively low-cost offerings, met overwhelming opposition from institute heads on the grounds that they had no significant projects on which they could put the computer to good use (Dorn, 1957). Still convinced of computers' usefulness, Shannon acquired the IBM 650 using a discretionary fund reserved for the Director and gave it to Frederick Sumner Brackett (1896-1988), the head of the Laboratory for Physical Biology at the National Institute of Arthritis and Metabolic Diseases (NIAMD - today called the National Institute of Diabetes and Digestive and Kidney Diseases, or NIDDK).

Brackett, like Shannon, went against NIH conventional wisdom by using and promoting computers, and found a poor reception to his excited but vague claims about a coming age in which computers would allow researchers to productively pursue "methods and approaches transcendent in promise of rapid, meaningful advances but formidable in scope and complexity" (Brackett, 1956 Apr). Further, for Brackett, the arrival of computers at NIH was inevitable: "the computer's presence and use at the NIH is one of form and timing rather than acceptance or rejection" (Brackett, 1956 Nov). Such talk, which closely paralleled the breathless salespitches made by IBM at the time, seems to have been met with great skepticism among NIH research personnel. Even NIH workers and associates sympathetic to introducing computing found themselves put off by the grandiose talk about what computers might someday do. In 1965 two of them joked: "It is somewhat surprising that someone did not suggest in the late 1950s that the digital computer was capable of everything including resurrecting the dead. Certainly every other claim was made!" (Stacy and Waxman, 1965, p. 2).

When all of the NIH's research institutes, including Brackett's own NIAMD, refused to provide space for the 650 , the facility for housing it ended up in the basement of Building 12, then an animal-storage facility. Arnold "Scotty" Pratt (1920-2003), who directed the facility, described the space as "unsatisfactory for human occupancy. Amid poor working conditions and a lack of reasonable expectations on the 
part of clients, the group running the 650 performed poorly, leading to a situation where, as Pratt recalled, "many senior scientists openly questioned the value of computing in their programs. These attitudes were heard and only partially discounted by the NIH leadership" (Pratt, 1984, pp. 460-461). It was only in 1966, towards the end of Shannon's 13-year tenure as NIH Director, that NIH established a permanent computing entity, the Division of Computer Research and Technology (now called the Center for Information Technology). ${ }^{9}$

Given the doubts about computers harbored by most NIH researchers and administrators in the late 1950s, it is hardly a surprise that Robert Ledley's request for NIH support to build a computing center was refused. A brief look at Ledley's 1959 proposal shows that it was full of forwardlooking, speculative language - there were many promises of the benefits computers would bring to biology but not much in the way of specific plans for how to achieve those results. A particularly egregious example was Ledley's promise that bringing in computers would re-orient sequencing away from traditional laboratory practices: "The use of a computer to analyze results may allow for significant simplification and further systematization of the chemical laboratory procedures by placing more of the burden on the analysis of the chemical results and less on the experimental processes involved" (Ledley, 1959).

Ledley's proposed three-step process to computerize protein sequencing was also long on promises and short on specifics:

1. "The previous work on protein analysis will be studied, and rules for analysis of the experimental results will be extracted in a form precise enough for computer programming."

2. "These rules will be tested on the computer, by means of experimental data already reported in the literature, to determine if they are adequate. If they are not, further analysis of previous work will be carried out."

3. "When a set of adequate rules is produced, it will be tried on an analysis of proteins not previously reported on, and on proteins for which only fragmentary knowledge exists. It is expected that as more experience is gained, more details and subtleties can be incorporated into the computer program" (Ledley, 1959).

The mechanisms of how "rules for analysis of the experimental results will be extracted" and "determine if they are adequate" were never

${ }^{9}$ CIT remains based in Building 12, and the animal-storage facilities were moved to an adjacent building in order to make more room for the computing staff and equipment. 
specified in the grant proposal. Vagueness about the differences between nucleotide base (DNA and RNA) sequencing and protein sequencing is understandable given that the genetic code had not been cracked at that point - indeed, there was still much confusion in 1959 about how, exactly, nucleotide bases coded for the amino acids that are the buildingblocks of proteins. So Ledley set aside that whole problem and moved on to an even grander vision of what the proposed sequencing computer program would do:

The automatic program will be written capable: (a) of automatically interpreting and compiling the input rules as actually written in sentential form; (b) of accepting data written in chemical language and automatically interpreting this into appropriate computer language; and (c) of automatically accepting methods for processing the data, according to the rules. (Ledley, 1959)

As of 2018, it is still generally not possible to get computer programs to follow any but the simplest commands inputted in the form of written sentences.

The final grand claim in Ledley's proposal involved using computers in "the application of quantum chemistry to molecular configurations of biological importance." This part of the project was to be carried out by Margaret Oakley Dayoff (1925-1983), an expert in quantum chemistry and electrochemistry who had worked extensively with computers during the course of her training and who had been Ledley's close friend since childhood. Dayhoff's particular role would be to use computers to unite chemistry and biology by using computers to simulate the behavior of molecules:

The fundamental laws of biochemistry are in reality just the result of the fundamental laws of quantum mechanics, which govern the atomic and molecular interaction. Although possible in concept, it is not generally feasible to use the laws of quantum mechanics to predict molecular phenomena, and such phenomena have had to be studied empirically. However, with the use of a computer advances can be made in various aspects of this field.

The advantage of the theoretical approach over the empirical approach is that the former can give a more exact or precise insight into the mechanisms of, for example, bond structure, molecular spacing, electron distribution and reactivity at specific points of a ring structure.... The significance of such better understanding is the ability to predict reality more accurately. (Ledley, 1959) 
What goes unmentioned here, though, is the scale of the molecules that are of "biological importance" and the degree to which representations of these molecules would need to be simplified to be process-able by a computer program in any reasonable amount of time.

When it came to subject of money, Ledley's proposal may have also been a difficult sell. To support the biomedical computing center for 1 year (1 April 1960-31 March 1961), he asked for $\$ 426,304$ (about $\$ 3.5$ million at 2018 values), with the expectation that each subsequent year would also be supported at roughly the same level of funding (Ledley, 1959). What was not included in this cost was the acquisition of a computer. Ledley had been promised by the USAF the use of two computers slated for retirement, FLAC I and FLAC II (Florida Automatic Computer), if he could find them a physical home. Though the FLAC machines were not compatible with IBM's more popular electronic computers, Ledley was an expert on the use of the computer on which the FLACs' design was based, the SEAC (Standards Eastern Automatic Computer) (November, 2012, p. 101). ${ }^{10}$

During the year following the NIH's decision not to support Ledley's biomedical computing center, Ledley focused his energy on building the NBRF and serving as an advocate, especially in the pages of Science, for the use of computers in biomedical research. By 1960 he had departed George Washington University to work at NBRF full-time, a move made possible by seed money granted by the National Academies of Sciences and by a small grant arranged by Shannon. For his part, Shannon remained enthusiastic about computing, and by late 1960 had circumvented the institute directors in order to provide about $\$ 40$ million to provide computers to biomedical researchers. To distribute this money, Shannon appointed Lee B. Lusted (1922-1994), a radiologist and Ledley's frequent writing partner, to head the NIH's Advisory Committee on Computers in Research (ACCR) (November, 2012, p. 110).

Essentially handed a blank check, the ACCR funded a dozen major research computing centers across the USA and played a direct role in fostering the development of computer technology, notably in the form of the MIT Lincoln Laboratory's LINC (Laboratory Instrument Computer), an important predecessor to personal computing. What the ACCR-funded projects did not produce, however, was much in the way of published research that would be useful in the clinic. For all the

${ }^{10}$ Administrators at George Washington University also balked at Ledley's plans to use the FLACs because of the estimated $\$ 300,000$ annual operating and maintenance cost. 
millions of dollars spent on computers, using them had not as of 1964, when the ACCR was shut down, produced any publicly-recognized medical breakthroughs (November, 2012, pp. 111-113).

Starting in the mid-1960s, the ACCR's successors, the NIH Computer Research Study Section (CRSS) and the Division of Research Facilities and Resources (DRFR), were incorporated into the normal $\mathrm{NIH}$ funding and oversight apparatus. Consequently, they mostly served to provide computers to help existing projects carried out or funded by NIH's various institutes, and when it came to funding more speculative ventures those institutes tended to be very tight with their resources. The reduction of the NIH budget as the conflict in Vietnam escalated further restricted the activity of these groups. When Ledley's organization, the NBRF, did receive significant NIH support, it generally was for projects with strongly evident clinical applications, such as his Film Input to Digital Automatic Computer (FIDAC) system, developed for automating karyotype analysis, and for Dayhoff's Atlas of Protein Sequence and Structure, which was a widely-used resource in the early sequencing community and which played a significant role in the formation of GenBank. When the NIH almost completely cut off support for the NBRF in 1973, Ledley scrambled to find a project that could attract enough non-NIH funding to pay the salaries of his researchers and staff; this led to the work for which he is best known, the 1974 development of the Automatic Computerized Transverse Axial (ACTA) scanner, the first whole-body CT scanner and the ancestor of many of the systems now widely used in clinics (Sittig, 2006, p. 467).

From the late 1970s to the late 1980s, the NIH tended to treat computers as workaday resources rather than instruments with vast transformative potential (Raub, 1971, p. 695). Early discussions of genomics, such as the 1985 Santa Cruz Workshop or Renato Dulbecco's 1986 public lectures and published commentary, got a lukewarm reception by the NIH. Tellingly, the initial leading institution of the Human Genome Project was not the NIH but the Department of Energy (Cook-Deegan, 1994, p. 100). During this same time, personal computers were becoming ubiquitous in everyday American life, and millions were experiencing the effects, both positive and negative, of Moore's law. In 1990, an Association of Computing Machinery workshop on the "History of Medical Informatics," that met in Bethesda, MD about a mile from the NIH campus, would look with great nostalgia on the early days of NIH computing, but also regret that the agency's early investment in computing had led to so little in the way of clinical breakthroughs (Blum and Duncan, 1990). 


\section{Genomics as the New Microelectronics}

One of the NBRF projects the NIH elected not to fund was Ledley's plan, first drafted in the late 1960s, to look seriously into how a "billiongate" computer would work and what it could bring to research. As was the case with Ledley's eon-spanning genetic code-cracking program and his biomedical computing center, the project seemed far-fetched in the age of thousand-gate machines. From Ledley's perspective in the 1960s, around the time Gordon Moore expressed his own vision of exponentially-growing numbers of transistors in affordable computers, a billion gates in a computer presented major concerns about reliability and repair, not to mention the human role in the design of such machines:

It may soon actually be possible to construct an electron circuit having many billions of gates. Assuming that this feat is technically possible, the problem still remains of exactly what can be accomplished with such an array of gates. A computer with a billion gates would be difficult to "design" in the conventional sense, because, among other reasons, no draftsman could draw a billion lines. Clearly, then, such a computer must be "self-organized." Further if a component breaks, it will not be possible to replace it, and hence the computer must be self-correcting and self-adaptive. (Ledley, $1970)^{11}$

What computing pioneers in Ledley's time had not seen coming was the sheer reliability of semiconductor-based transistors, or Intel's rapid progress in finding ways to build machines that could etch microscopic circuits onto silicon wafers. Something about as powerful as Ledley's billion-gate computer arrived in the home around the early 1990s, even though self-repairing, self-organized hardware did not come to be. Another thing Ledley had not foreseen, not even in his wildest speculations, was the degree to which the NIH and indeed the broader American society came to embrace - to the point of making it a major priority - technological change (especially as embodied by "innovation") as an end unto itself.

The prioritization of "innovation" in medical research did not just emerge like some natural phenomenon; rather, it was constructed. In the story of sequencing, parallels to Moore's law abound, even if the comparison between microelectronics and sequencing is problematic. The idea that sequencing is (and will continue to be) speeding up and

11 Ledley recalled that he had spent several years toying with the idea of a "billiongate computer" before completing the "final" draft in 1970. 
becoming cheaper at an exponential rate may not have a well-known name like Moore's law does - the term "Carlson Curve," named for researcher/entrepreneur Rob Carlson by The Economist in 2006, never caught on (The Economist, 2006). But like Moore's law, which served as a goad to push companies like Intel to miniaturize and economize, this phenomenon is a largely a story of setting a goal for the future and then working very hard to achieve it. For the genomics community, that goal was to find a way to sequence an entire human genome for $\$ 1000$, and it was set in 2002 when sequencing a genome cost well over \$10 million.

Like the microelectronics community starting in the 1960s, there was a sense among genomics workers in the early 2000s that their field was exceptional, especially when it came to budgets and the pace of technological change. Already, they had defied institutional gravity to achieve the first complete sequencing of the human genome in 2003, 2 years ahead the target date of 2005 they had set in 1990 (when the Human Genome Project began) and considerably under budget (NHGRI, 2010). For the typical taxpayer the completed human genome was a wondrous thing, though also highly inaccessible and irrelevant to their personal health - it was very much similar to the view a typical American might have in 1965 of the IBM 360, which did amazing things but cost millions of dollars and required a great deal of specialized knowledge to operate. To make genomics relevant to most people, the price of sequencing a human genome had to come way down.

In 2002, the NHGRI held a meeting at which the long-term future of genomics was discussed. At the time, the conventional wisdom held that the cost of sequencing could be driven down 100-fold over the coming 5 years by continuing to refine Sanger sequencing, which had been the most popular method of sequencing since it was introduced in 1977 and which involves attaching fluorescent dyes to nucleotide bases. This would be a huge leap, but genomes that cost between $\$ 100,000$ and $\$ 1,000,000$ to sequence were still nowhere near affordable. To get the genome to the point where it might be ordered up (like an MRI scan) by a physician - and that was indeed the expressed hope - sequencing the genome would need to cost thousands or even hundreds of dollars (Mardis, 2006, p. 112). ${ }^{12}$ Jeffery Schloss, then Director of NHGRI's Division of Genome Sciences, recalled: "Somebody threw out, to great rolling of eyes, 'a thousand dollars"' (Hayden, 2014, p. 294). Getting to $\$ 1000$, which became as much a mantra as an actual goal by 2010 or so,

12 Specifically Mardis stated in Mardis (2006): "In this paradigm, the cost of determining an individual genome sequence would fall to a price of around $\$ 1,000$, placing it firmly in the realm of advanced clinical diagnostic tests." 
would mean developing some technology other than Sanger sequencing. ${ }^{13}$ As Trever Hawkins of Amersham Biosciences put it in 2002, "Miniaturization and high-throughput techniques can only do so much. They might reduce costs to $\$ 30,000$ per genome, but to get to $\$ 1000$, it's going to take some new technologies" (Westpha, 2002).

Bringing down the cost of sequencing a genome required a departure from business as usual for the NIH, which was to carefully vet projects for clinical relevance before allocating funding to them. Indeed, following the "NIH Roadmap for Medical Research" of Director Elias Zerhouni (2002-2008), the agency had made a priority during the first decade of the twenty-first century of supporting "translational research" and other activities that led to clinical results (NIH, 2008). Given the huge gap between listing base-by-base the human genome and understanding what those bases do, it was difficult to find any direct clinical application to most genomics research and development. Questions about applicability and usefulness had sunk efforts in the 1950s and 1960s to establish NIH support for sequencing and computerization. Grand talk, coming from Robert Ledley or even NIH Director Shannon, about the transformative potential some unproven, expensive technology offered to medical research and clinical care, was generally not well received in Eisenhower or Kennedy's America. Compared even to the Apollo Program, which was based on proven and rapidly-developing (thanks to the nuclear arms race) ballistic rocket technology, computerized biomedicine was a far-fetched venture - it lacked the technology, the motivation (of researchers, clinicians, and computer-makers), and the feasibility of a program built upon wellknown successes (Hirsch, 2008).

By the 2000s and 2010s, American taxpayers and the NIH were much more tolerant of investing in innovation for its own sake or indeed for the explicit aim of disrupting the status quo. The spectacular success of startups in computing (and to a much lesser-known degree, biotech) had shown Americans how the creative work of a few inventors and entrepreneurs could change the way Americans went about their work and indeed their daily lives. Apple, Microsoft, Google, and Facebook had become household names. Starting around 2003, NIH granted NHGRI an extraordinary degree of autonomy when it came to deciding how grant money ought to be allocated. As Hayden put it: "The mixture of applied and academic research within a single programme was uncommon at the National Institutes of Health (NIH), the NHGRI's

${ }^{13}$ For the reading public, the notion of the ultra-cheap genome was popularized in works like Davies (2010). 
parent agency. The project was also more nimble than the typical NIH grant programme because it allowed the agency to make small awards for work considered promising but risky" (Hayden, 2014, p. 294). This activity accelerated when then-NHGRI head Francis Collins was appointed NIH Director in 2009.

Instead of their pie-in-the-sky talk being dismissed, researchers like George Church, who announced in 2002 (and long before such feats were feasible with the technology on hand), "We are proposing to give people their own sequence if they'll have it," found themselves receiving NIH funding. Thanks in large part to at least a dozen P50 grants (a type of grant targeted at research centers that "support[s] any part of the full range of research and development from very basic to clinical"), Church and his collaborators at Center for Transcriptional Consequences of Human Genetic Variation (CTCHGV) were able to develop (over the course of a decade) new technologies to bring down the cost of sequencing (NIH, 2016). ${ }^{14}$

Setting aside the need for clinical applicability, the CTCHGV and other NHGRI-funded Centers of Excellence in Genomic Science (CEGS) have as their top-listed quality being "highly innovative, being designed to develop new concepts, methods, technologies, or ways to produce or analyze comprehensive data sets, or on a particular genomescale biomedical problem, or on other ways to develop and use genomic approaches for understanding biological systems and/or significantly furthering the application of genomic knowledge, data and methods towards clinical applications" (NHGRI, 2016c). Evaluation for CEGS also is centered on development of a "product," one that demonstrably improves sequencing, rather than something like a successful clinical trial. ${ }^{15}$ Much earlier NIH-funded genomics projects, it should be noted, were also evaluated on the basis of "innovation." For instance, the Genetic Map, a "fine-grained genetic map" that was the "first goal of the genome project," faced funding challenges in the early 1990s because it was not sufficiently "innovative." The project's leader, Helen Donis-Keller (then of Washington University), complained in 1990, "my first love is the genetic linkage map, to create a high-quality biological tool... this is just not the kind of work that excites most peer reviewers...." She noted that an NIH study section declined to support

${ }^{14}$ For example: see: http://grantome.com/grant/NIH/P50-HG005550-05. (Grantome is a private venture that runs a database containing information related to genomics grants.)

${ }^{15}$ The rise of the phenomenon of a biology research project being assessed on the basis of production of data (and little else) is discussed in Leonelli (2016) and Stevens (2013). 
her work on the grounds that it was "not innovative." To that judgment she replied, "I never said it was innovative. But it is important and doable" (Roberts, 1990, p. 282).

High-risk, high-yield investments by the NHGRI are so numerous that they have become almost commonplace over the last decade. For instance, thousands of NHGRI grants have gone to university labs and startup companies pioneering technologies like nanopore sequencing (Sanderson, 2008, p. 25). Oxford Nanopore Technologies, a UK-based startup that received about $\$ 9$ million from NHGRI's total $\$ 90$-million investment in nanopore technologies, has demonstrated a product, MinION, that reportedly sequenced large portions of a human genome for thousands of dollars in a matter of days (Oxford Nanopore Technologies, 2016).

In terms of number of lives saved, the effects of these amazing genomics advances have so far been un-newsworthy. But when other metrics are used to present the payout of the investment into developing genomics, the results are quite impressive, especially if one takes at face value the notion that innovation is good. A case in point is formed by the two controversial reports released on 11 May 2011. The more widely-read and more sensational of the two reports was "Economic Impact of the Human Genome Project," prepared by the Battelle Technology Partnership Practice, a non-profit technology consulting outfit whose parent company, Battelle, has the motto: "The Business of Innovation." The report, which was commissioned by the Life Technologies Corporation (now absorbed into Thermo Fisher Scientific, a major producer of genetic testing and other laboratory equipment), concluded that "the $\$ 3.8$ billion spent on the HGP may well represent the best single investment ever made in science," estimating the payout of this investment at close to \$796 billion (Tripp and Grueber, 2011, front cover). The Battelle report's view of the relationship between society, innovation, and genomics goes like this: "Modern developed societies are driven forward by innovation-typically technological innovation. The HGP and associated sequencing projects have advanced the state of innovation and technology and resulted in broad economic impacts..." (Tripp and Grueber, 2011, p. 58).

The other report published that day was "An Economic Engine NIH Research, Employment, and the Future of the Medical Innovation Sector," written by Everett Ehrlich for United for Medical Research (UMR), a lobbying effort backed by several major biomedical firms and research universities that advocates for more NIH funding. That report emphasized the NIH's role in fostering the growth of the "medical 
innovation sector" and endeavored to make readers aware of the "symbiotic relationship between NIH basic research funding and subsequent investment and innovation in the private economy" (Ehrlich, 2011, p. 1). The UMR report also raised the specter of unfriendly foreign competition to America's genomics effort and proposed (without ever defining) "innovation" as the solution:

The best response to this challenge is to continue to compete through innovation. Ultimately, to compete on the basis of price with providers, researchers, or manufacturers from India or China is to move toward their lower standard of living. But staying ahead of these competitors through continued innovation allows the U.S. to maintain its position of leadership in the various medical innovation industries. (Ehrlich, 2011, p. 9)

The NHGRI welcomed both reports, with the Office of the Director releasing a news feature, "Calculating the economic impact of the Human Genome Project," recapping their highlights from the agency's perspective (Gitlin, 2013). Beyond the NIH, the reception of the reports' claims was decidedly cooler. Some economists agreed with the reports' numbers, but disagreed with the argument that government-funded research was the major driver of economic growth related to genomics (Wadman, 2013). Nature reported that Bruce Weinberg, an economist at Ohio State University, asserted that the Battelle report was attempting to measure the wrong phenomena, saying "The reality here is we are not really measuring what we want to measure. Not: "how many jobs were created?', but 'how many lives were saved?"' Nature further reported that another economist, Robert Topel of the University of Chicago's School of Business, took issue with the analogy Battelle drew between genomics spending and military spending:

Topel likens Battelle's approach to the argument that military spending is worthwhile because it keeps many people employed building ships and planes, or serving in uniform. In fact, those people could be engaged in other pursuits, and should be counted as costs, rather than benefits, of military spending.... The true benefit of such spending, Topel adds, is increased security - which, like improved health, is much harder to measure. (Wadman, 2013) 


\section{Conclusions}

There is an alternative to "innovation" and that is the dull, plodding, and necessary work of maintenance. ${ }^{16}$ Activities like ensuring the reliable delivery of high-quality products and establishing (and upholding) a field's standards are generally ignored by the public and are associated with power utilities or the more boring blue-chip companies rather than cuttingedge scientific and technological development. But it turns out that Gordon Moore's company, Intel, and the NHGRI are both exceedingly good at maintenance, even if there is not much public excitement about that fact.

Already a great deal of myth-busting is being carried out among historians of computing. Much has been done to dispel the body of mythology surrounding Gordon Moore's quip that "Moore's law is a violation of Murphy's law... everything gets better and better" (The Economist, 2005). Granted, historians have shown that being open to disruptive creativity is a big part of helping Moore's law seem to violate Murphy's law, but so are the less glamorous activities of building infrastructure, coordinating resources, and establishing (and enforcing strict adherence to) a wide variety of standards.

Genomics is arguably even more saturated with "innovation talk" than microelectronics. Successful, long-shot investments in hip startups make headlines, whether they are in computing or genomics. So do charismatic presentations by the likes of Eric Lander, who bragged about progress in sequencing that "beats Moore's law hands down" and who lauded the new generation of sequencing machines as "wonderfully disruptive technology" (Herper and Langreth, 2007). Such talk attracts investors' dollars and positive attention from the legislators who fund agencies like the NIH. Add to that a sense of exceptionalism, a notion that the conventional rules of institutional behavior and economics do not apply, and you have something that promises to be transformative. The Human Genome Project finished under budget and ahead of schedule, much like Donald Trump's claims about the recent renovation of the Old Post Office Pavilion into the Trump International Hotel. On that Trump remarked: "'under budget and ahead of schedule.' We don't hear those words too often in government, but you will" (O'Keefe et al., 2016). ${ }^{17}$ As this article goes into review, NIH Director (and former

${ }^{16}$ I am indebted to the organizers of and participants in "The Maintainers" conference of 7-9 April 2016 held at the Stevens Institute of Technology for proposing and refining this concept (http://themaintainers.org/).

17 Trump's overall view of the way NIH traditionally operates is markedly negative. As of mid-2018, he has said little other than "I hear so much about the NIH, and it's terrible" (Mullin, 2016). 
NHGRI head) Francis Collins appears to be set to continue in his position under the Trump administration.

Whether America is led by a Clinton, a Bush, an Obama, or a Trump, the innovation rhetoric persists, and the NHGRI in its scramble for funding has mastered that language. What this masks are the decades of effort the institute has put into building the intellectual, institutional, and material infrastructures of genomics and to setting forth (and enforcing) standards of measurement, value, and behavior (in the form of the Bermuda Principles, the NHGRI's guidelines for sharing data, which call for the quick, open release of DNA sequence data to the public) for the field. These may not be exciting in terms of building a triumphalist narrative or engaging a public hoping for quasi-miraculous breakthroughs, but they are where much of the most important work happens. The good news is that although this story remains largely untold, there is now the means to do so thanks to the NHGRI's commitment to building the National Human Genome Research Institute Archive. If the archive does indeed grow into the candid collection of many thousands of NHGRI documents that was envisioned, historians will have the opportunity to look past the institute's (and the broader genomics community's) public-facing and legislator-facing and administrator-facing rhetoric to learn how an important new field was constructed.

\section{Open Access}

This article is distributed under the terms of the Creative Commons Attribution 4.0 International License (http://creativecommons.org/ licenses/by/4.0/), which permits unrestricted use, distribution, and reproduction in any medium, provided you give appropriate credit to the original author(s) and the source, provide a link to the Creative Commons license, and indicate if changes were made.

\section{References}

BBC News. 14 December 2016. "Trump Praises Tech Leaders for 'Incredible Innovation."” http://www.bbc.com/news/world-us-canada-38323260.

Blum, Bruce I. and Duncan, Karen (eds). 1990. A History of Medical Informatics: Proceedings of Association for Computing Machinery Conference on History of Medical Informatics. New York: ACM Press.

Brackett, Frederick S. 13 April 1956. "Electronic Data Processing and Computing Equipment: The Meaning for NIH." Memorandum to James Shannon. NIH Elec- 
tronic Data Processing Collection (RG 443 G2A 64, box 90, file 53). National Archives.

21 November 1956. "Report of Committee," Memorandum to James Shannon. NIH Electronic Data Processing Collection (RG 443 G2A 64, box 90, file 51). National Archives.

Brock, David C. 2006. "Reflections on Moore's Law." David C Brock (ed.), Understanding Moore's Law: Four Decades of Innovation. Philadelphia: Chemical Heritage Press, pp. 87-108.

Caban, Teresa Zayas and Chaney, Kevin (Office of the National Coordinator for Health Information Technology). 11 April 2017. "The Precision Medicine Era is Dawning." Health IT Buzz, accessed 7 August 2018, https://www.healthit.gov/buzz-blog/ precision-medicine/precision-medicine-era-dawning/.

Collins, Francis and Varmus, Harold. 2015. "A New Initiative on Precision Medicine." The New England Journal of Medicine 372: 793-795.

Cook-Deegan, Robert M. 1994. "Origins of the Human Genome Project." Risk: Health, Safety \& Environment 5(2): 97-118.

Davies, Kevin. 2010. The \$1,000 Genome: The Revolution in DNA Sequencing and the New Era of Personalized Medicine. New York: Free Press.

Dorn, Harold. 29 March 1957. "Purchase Cost of IBM 650 Equipment." Memorandum. NIH Electronic Data Processing Collection (RG 443 G2A 64, box 90, file 52). National Archives.

Ehrlich, Everett. 11 May 2011. “An Economic Engine NIH Research, Employment, and the Future of the Medical Innovation Sector." United for Medical Research. Last accessed 7 August 2008, http://www.unitedformedicalresearch.com/wp-content/ uploads/2012/07/UMR_Economic-Engine.pdf.

Feero, W.G. 2014. "Clinical Application of Whole-Genome Sequencing: Proceed With Care." The Journal of the American Medical Association 311(10): 1017-1019.

Fortun, Michael. 1999. "Projecting Speed Genomics." Michael Fortun, Everett Mendelsohn (eds.), Practices of Human Genetics: International and Interdisciplinary Perspectives, Sociology of the Sciences Yearbook 19. Dordrecht: Kluwer, pp. 25-48.

Garcia-Sancho, Miguel. 2012. Biology, Computing and the History of Molecular Sequencing: From Proteins to DNA, 1945-2000. Basingstoke: Palgrave Macmillan.

Gates, Bill. 16 November 1997. "Remarks to COMDEX.” Las Vegas, Nevada. Internet Archive Wayback Machine, last accessed 7 August 2018, http://web.archive.org/ web/20090114203618/http://www.microsoft.com/presspass/exec/billg/speeches/1997/ comdex97.aspx.

Gitlin, Jonathan Max. 12 June 2013. "Calculating the economic impact of the Human Genome Project." News Feature from the Office of the Director, National Human Genome Research Institute. Last accessed 7 August 2018, https:/www.genome.gov/ 27544383/calculating-the-economic-impact-of-the-human-genome-project/.

Green, Eric D., Guyer, Mark S. and the National Human Genome Research Institute. 2011. "Charting a course for genomic medicine from base pairs to bedside." Nature 470: 204-213.

Gutierrez, Alberto (FDA) to Ann Wojcicki (23andMe, Inc.). 22 November 2013. "Warning letter, Re: Personal Genome Service (PGS)." FDA Document Number GEN1300666. https:/www.fda.gov/ICECI/EnforcementActions/WarningLetters/ ucm376296.htm.

Guttmacher, Alan E. 24 September 2009. "The Future of Human Genome Research and Its Implications for the Education of Health Professionals," NCHPEG Annual 
Meeting, accessed on 17 December 2017, http://www.nchpeg.org/documents/ Guttmacher.pdf.

31 August 2009. "Drivers of Innovation: The Human Genome Project, Microarrays, the HapMap, and the $\$ 1000$ Genome." The National Academies, accessed on 8 August 2018, https://sites.nationalacademies.org/cs/groups/pgasite/ documents/webpage/pga_053080.pdf.

Guttmacher, Alan E. and McGuire, Amy L., Ponder, Bruce and Stefánsson, Kári. 2010. "Personalized Genomic Information: Preparing for the Future of Genetic Medicine." Nature Reviews Genetics 11(2): 161-165.

Haigh, Thomas. 2001. "The Chromium-Plated Tabulator: Institutionalizing an Electronic Revolution, 1954-1958." IEEE Annals of the History of Computing 23(4): 75104.

Hayden, E. C. 2014. “The \$1,000 Genome.” Nature 507: 294-295.

Herper, Matthew and Langreth, Robert. 18 June 2007. "Will You Get Cancer?" Forbes, last accessed 7 August 2018, http://www.forbes.com/forbes/2007/0618/052.html/.

Hillaryclinton.com (Campaign Website). 27 June 2016. "Fact Sheet: Hillary Clinton's Initiative on Technology \& Innovation." https://www.hillaryclinton.com/briefing/ factsheets/2016/06/27/hillary-clintons-initiative-on-technology-innovation/.

Hirsch, Matthew. 2008. "Apollo's Stepchildren: New Works on the American Lunar Program." Technology and Culture 49: 449-455.

Hughes, Sally Smith. 2011. Genentech: The Beginnings of Biotech. Chicago:University of Chicago Press.

Ledley, Robert S. 1955. "Digital Computational Methods in Symbolic Logic, with Examples in Biochemistry." Proceedings of the National Academy of Sciences of United States of America 41: 498-511.

1959. "Biomedical Computer and Biomathematics Research Center." Application for Research Grant, National Institutes of Health, B-RG-2075 (formerly RG 7323), submitted 1 November 1959. Robert S. Ledley Papers, National Biomedical Research Foundation (collection now being processed by the National Library of Medicine, Bethesda, MD).

1970. "Realization of a Billion-Gate Computer." Technical report for National Biomedical Research Foundation. Reprinted in Robert S. Ledley et al. 1973. NBR Research Accomplishments 1960-1970.

Ledley, Robert S. and NBRF Staff. 1973. National Biomedical Research Foundation Research Accomplishments: 1960-1970. Washington, D.C.: NBRF.

Leonelli, Sabina. 2016. Data-Centric Biology: A Philosophical Study. Chicago: The University of Chicago Press.

Mardis, Elaine R. 2006. “Anticipating the 1,000 Dollar Genome.” Genome Biology 7(7): 112.

Maughan, Tim. 2017. "The Promise and the Hype of 'Personalised Medicine'." The New Bioethics 23(1): 13-20.

McFarland, Matt. 16 November 2016. "Obama was an innovation junkie. Will Trump follow in his footsteps?" CNN, http://money.cnn.com/2016/11/16/technology/ trump-innovation-white-house/.

Microsoft. 22 April 2018. "Microsoft AI: Empowering Innovators ft. Common." https://www.youtube.com/watch?v = Z5OWdqfAYfw.

Miller, Perry. 1965. The Life of the Mind in America. New York: Harcourt.

Moore, Gordon E. 1965. "Cramming More Components onto Integrated Circuits." Electronics 38(8): 114-117. 
2006 "Moore's Law at Forty." David C Brock (ed.), Understanding Moore's Law: Four Decades of Innovation. Philadelphia:Chemical Heritage Press, pp. 67-86.

Mullin, Emily. 16 November 2016. "What's Trump's Plan for U.S. Biomedical Research?" MIT Technology Review, last accessed, 7 August 2018, https://www. technologyreview.com/s/602856/whats-trumps-plan-for-us-biomedical-research/.

National Human Genome Research Institute. 2016a. "The Human Genome Project Completion: Frequently Asked Questions." Last modified on 30 October 2010, https://www.genome.gov/11006943/human-genome-project-completion-frequentlyasked-questions.

-2016b “The Cost of Sequencing a Human Genome.” Last modified on 7 July 2016. https://www.genome.gov/27565109/the-cost-of-sequencing-a-human-genome.

— 2016c "Centers of Excellence in Genomic Science." Last modified on 31 October 2016. https://www.genome.gov/10001771/.

National Institutes of Health. 24 September 2008. "Media Advisory: Elias A. Zerhouni to End Tenure as Director of the National Institutes of Health." Last accessed 7 August 2018, https://www.nih.gov/news-events/news-releases/elias-zerhouni-endtenure-director-national-institutes-health.

National Institutes of Health. 21 July 2016. "Types of Grant Programs.” Last updated 21 July 2016, https:/grants.nih.gov/grants/funding/funding_program.htm\#PSeries.

- 2016. "Ask Your Doctor... About Computers." IEEE Annals of the History of Computing 38(1): 3-5.

November, Joseph A. 2012. Biomedical Computing: Digitizing Life in the United States. Baltimore: Johns Hopkins University Press.

Nye, David. 1994. American Technological Sublime. Cambridge: MIT Press.

O'Keefe, Ed, Sullivan, Sean and Zezima, Katie 26 October 2016. "Trump Leaves Campaign Trail to Open His New Downtown D.C. Hotel." The Washington Post.

Office of the Press Secretary, The White House. 21 October 2015. "Fact Sheet: The White House Releases New Strategy for American Innovation, Announces Areas of Opportunity from Self-Driving Cars to Smart Cities." https://obamawhitehouse. archives.gov/the-press-office/2015/10/21/fact-sheet-white-house-releases-new-strategyamerican-innovation.

Oxford Nanopore Technologies. 20 October 2016. "Human Genome on a MinION." Last accessed 7 August 2018, https://nanoporetech.com/about-us/news/humangenome-minion.

Pratt, Arnold W. 1984. "Computers in Biomedical Research." DeWitt Stetten (ed.), NIH: An Account of Research in Its Laboratories and Clinics. New York: Academic Press, pp. 456-480.

Raub, William F. 1971. "The Life Sciences Computer Resources Program of the National Institutes of Health." In Proceedings of the 26th Annual Conference of the Association of Computing Machinery, pp. 693-700. New York: Association for Computing Machinery.

Reiser, Stanley Joel. 2009. Technological Medicine: The Changing World of Doctors and Patients. Cambridge: Cambridge University Press.

Roberts, Leslie. 1990. "Whatever Happened to the Genetic Map?' Science 247: 281-282.

Russell, Andrew and Vinsel, Lee. 2016. "Hail the Maintainers," Aeon. Last modified on April 7, 2016, https://aeon.co/essays/innovation-is-overvalued-maintenance-oftenmatters-more.

2017. "Let's Get Excited About Maintenance!" The New York Times, 22 July 2017. 2018 "After Innovation, Turn to Maintenance." Technology and Culture 59(1): 1-25. 
Safian, Robert. 21 February 2018. "Why Apple is the World's Most Innovative Company." Fast Company. Fast Company is the keeper of the oft-cited "World's Most Innovative Companies" list. https://www.fastcompany.com/40525409/why-apple-isthe-worlds-most-innovative-company.

Sanderson, Katharine. 2008. "Personal Genomes: Standard and Pores." Nature 456: 23-25. http://www.nature.com/news/2008/081105/full/456023a.html.

Shannon, James. 1965. "Foreword." Ralph W Stacy, Bruce D Waxman (eds.), Computers in Biomedical Research. New York: Academic Press.

Sittig, Dean, Ash, Joan and Ledley, Robert S. 2006. "The Story Behind the Development of the First Whole-body Computerized Tomography Scanner as Told by Robert S. Ledley." Journal of the American Medical Informatics Association 13(5): 465-469.

Stacy, Ralph W. and Waxman, Bruce D. 1965. "Introduction." Ralph W. Stacy and Bruce D. Waxman (eds.), Computers in Biomedical Research. New York: Academic Press.

Stevens, Hallam. 2011. "Dr. Sanger, Meet Mr. Moore: Next-Generation Sequencing is Driving New Questions and New Modes of Research." Bioessays 34(2): 103-105.

2013. Life out of Sequence: A Data-Driven History of Bioinformatics. Chicago: The University of Chicago Press.

Sunder Rajan, Kaushik. 2006. Biocapital: The Constitution of Postgenomic Life. Durham: Duke University Press.

The Economist. 23 March 2005. "Moore's Law at 40: Happy Birthday: The Tale of a Frivolous Rule of Thumb," accessed 7 August 2018, http://www.economist.com/ node $/ 3798505$.

- 31 August 2006 “Special Report: Life 2.0," accessed 7 August 2018, http://www. economist.com/node/7854314.

Tripp, Simon and Grueber, Martin. 11 May 2011 "Economic Impact of the Human Genome Project." Battelle Technology Partnership Practice. Front cover. Last accessed 7 August 2018, https://www.battelle.org/docs/default-source/misc/battelle2011-misc-economic-impact-human-genome-project.pdf.

Wadman, Meredith. 2013. "Economic Return from Human Genome Project Grows." Nature News. 12 June 2013. https://doi.org/10.1038/nature.2013.13187. Last accessed 7 August 2018, https://www.nature.com/news/economic-return-from-human-genome-project-gro ws-1.13187.

Westpha, Sylvia Pagán. 12 October 2002. "Race for the $\$ 1000$ genome is on." New Scientist.

Wetterstrand K. A. "DNA Sequencing Costs: Data from the NHGRI Genome Sequencing Program (GSP)." National Human Genome Research Institute. Last modified on 15 April 2018, https://www.genome.gov/sequencingcostsdata/.

Wikipedia. "Instructions per second," last accessed 1 February 2017, https://en.wikipedia. org/wiki/Instructions_per_second. 